\title{
Welfare economic assessment of processing impregnated waste wood
}

\author{
V. Kjærbye ${ }^{1}$, A. Larsen ${ }^{1}$, B. Hasler ${ }^{2}$, M. R. Schrøder ${ }^{1} \&$ J. Cramer ${ }^{3}$ \\ ${ }^{I}$ Akf, Institute of Local Government Studies, Denmark \\ ${ }^{2}$ National Environmental Research Institute, Denmark \\ ${ }^{3}$ Force Technology
}

\begin{abstract}
Waterproof waste wood contains a series of chemicals, especially chromium, copper and arsenic, which can be hazardous to human health and the natural environment in concentrated quantities. In this welfare economic analysis the economic and environmental consequences of four methods of processing impregnated waste wood are considered and compared: deposition, incineration, gasification and an extraction process. The quantity of impregnated waste wood is not a limiting factor for the individual method. The analysis includes both the socio-economic and the environmental consequences of applying these methods. The results of the analysis show that incineration and gasification are the cheapest wood processing methods in a welfare economic perspective. The reason is that both methods produce heat and thereby avoid the use of other more polluting fuels. Deposition is quite expensive, and it neither recycles nor uses the energy in the wood. If one only looks at the direct costs of the processes, and does not estimate and include the value of the environmental consequences, the differences between the methods are smaller. The basis for the article is a report by the authors for The Danish Environmental Protection Agency. The authors would like to express their gratitude to the agency for funding.
\end{abstract}

Keywords: impregnated waste wood, welfare economic assessment.

\section{Introduction}

This analysis is launched to provide answers as to how society should obtain a welfare economic optimal treatment of impregnated waste wood. The welfare 
economic analysis includes both the direct costs of processing the wood as well as the environmental consequences.

Impregnated waste wood is most problematic when it comes to the removal, as the waste from the impregnation of the wood is minor. Some of the heavy metals and organic solvents are washed out to the ground and to groundwater during the lifespan of the impregnated wood, but most of the heavy metals will remain in the wood until the wood is removed. By the removal the contents of chromium, copper and arsenic are especially problematic. These contents are not removed by ordinary combustion, but will remain in the residual products, in the slag and the ashes.

As a consequence of the Danish Waste Policy (Waste 21) all impregnated wood, except the creosote impregnated, should be assigned to a deposit facility at present, and this has been the situation since 2001. The creosote impregnated wood can be treated in special combustion plants.

The wood impregnated with creosote does not result in these residual products and waste after combustion, however [3], and therefore the treatment of creosote wood is not subject to the present welfare economic assessment.

The current practice is embedded in the so-called 'hierarchy of waste'. This hierarchy is built so that recycling is weighted higher than incineration, which is weighted higher than deposition. It is an ongoing discussion as to what extent this hierarchy should be used, and the discussion has been intensified in Denmark, among other reasons because the pollution with chemicals and other compounds. The effects of chromium, copper and arsenic from impregnated wood in the environment depend on the concentration to which humans and nature is exposed, but they stretch from locally irritating to poisonous and cancer-causing. There are some positive environmental effects from processing impregnated waste wood, and that is recycling or the displacing of other more polluting fuels.

This paper examines the economic as well as the environmental consequences of four methods of processing. These four methods are assessed: deposition, incineration, gasification (by processes at the plant 'Kommunekemi') and an extraction process (RGS90 Watech). When the wood is deposited the energy is not used nor is it recycled. When incinerating, the energy is utilised, but there is no recycling. The methods of both Kommunekemi and RGS90 Watech utilise the energy and have an element of recycling; hence they are both ranked higher in the hierarchy of waste.

\section{Data and scenarios}

\subsection{Data}

The input data to the analysis comprise data on potential amounts of impregnated wood, the composition of the wood and budget data from the processing plants. The content of the budget data is partly confidential and therefore not described further here. 
Impregnated wood is mainly in poles, sleepers and waste wood from public waste collections. The total amount of impregnated wood is estimated to 50,000 tons in 2004, and is projected to be about doubled in 2010 [1]. In the waste strategy launched by the Danish Government in 2003 [2] it is assumed that approximately 4 million tons impregnated wood is accumulated since the $1960 \mathrm{~s}$ and that this waste should be processed in 40 years' time. According to this strategy the energy and raw materials should be utilised.

Impregnated wood can be divided into two categories; the creosote treated and the non-creosote treated. The creosote treated wood is burned in incineration plants in a process that does not impact the environment. The non-creosote treated wood, however, burdens the environment and this must be dealt with when processing it. Therefore, this analysis focuses solely on the non-creosote treated wood when comparing the methods. This wood is mostly found in poles and waste wood from public collections hence only wood from these sources is included.

Data from 5 tons of impregnated wood collected by Kommunekemi are used to estimate the composition of the wood [12].

\subsection{Scenarios}

The baseline scenario represents the current treatment of the waste wood, where creosote treated wood is burned and the salt impregnated wood is deposited.

Two alternative scenarios are assessed; a maximum and a minimum scenario. They are divided so that the maximum scenario provides the best economy for the plants. For deposition this means a higher specific weight $\left(\mathrm{kg} / \mathrm{m}^{3}\right)$ in the maximum scenario. The difference for the other three processing methods is that the calorific value is higher in the maximum scenario as compared to the minimum. For the maximum and minimum scenarios the content of $\mathrm{Cu}, \mathrm{Cr}$ and As in 'clean' impregnated wood is assumed to be close to constant, as the leaching of the compounds mainly happens in the first years of the lifetime of the wood.

The costs of the alternative processing methods are assessed as compared to the baseline scenario, i.e. the current treatment. In the baseline the treatment is paid by the taxpayers at municipal level.

\section{Method}

The four methods of processing impregnated waste wood: deposition, incineration, gasification and extraction, are compared with respect to the costs and the benefits of each, using a welfare economic assessment method.

\subsection{The welfare economic assessment}

The basic idea behind a welfare economic analysis of benefits and costs is to determine the total effect of the project on the welfare of society as a whole. In the present analysis the 'project' is the processing of impregnated waste wood. The welfare economic assessment therefore implies estimation and prediction of 
the changes in consumption possibilities of the members of the society. Seen from a welfare economic viewpoint, the state or other governmental levels should implement policies where the social benefits derived from the policy exceed the economic or social costs associated with the implementation.

The assessment of the welfare economic costs and benefits takes its point of departure in a description of the consequences. The measurement of the welfare economic costs and benefits is, in other words, based on expectations of the consequences of the alternatives for processing impregnated wood. For the measurement of the relative marginal welfare economic consequences, so-called calculation prices are used. The so-called accounting price method is used for the estimations of the welfare-economic costs, and the principles behind this method are presented in more detail in Møller et al. [4] and Birr-Pedersen [5].

The welfare economic evaluation determines benefits and costs from the point of view of the economy of the society as a whole, and includes two sub-analyses:

1. The analysis of the financial consequences, upon which the distribution effects between the different actors can be measured, e.g. the effects for the processing plants, the municipalities etc. The prices used are the market prices either paid on the market for inputs in the form of producer or consumer goods, or obtained on the market from selling outputs, including all non-refundable taxes and subsidies. In the case of consumer goods all taxes are non-refundable and should therefore be included in the price [5].

2. The welfare economic analysis, where economic costs and benefits to the economy as a whole are measured with market prices adjusted to reflect the true economic costs and benefits to society. The external effects, i.e. the non-marketed effects of the environmental changes are as far as possible included in the welfare economic analysis.

The financial analysis that is performed upon market prices is the basis for the welfare-economic analysis. The inputs to this part of the analysis are delivered by the processing plants. In the economic analysis in this study, intersectoral transfers between sector and sub-economies are not counted, e.g. between the state and the processing plants.

In order to determine the correct price for the inputs used in the production process in cases where the project's output is producer goods, the prices are adjusted to reflect the consumer's willingness to pay:

- For consumer goods produced the price is simply the prevailing market price, gross of taxes and subsidies. No adjustments need to be made on these prices.

- For producer goods the market prices reported by the processing plants need to be adjusted, because consumers are also willing to pay sales tax and maybe other product specific taxes levied on the good during the production process. Møller et al. [4] suggest increasing producer prices of domestically traded goods and services (net of refundable taxes) with a so-called 'net-taxfactor' of 1.17, and for internationally traded goods a factor of 1.25 is suggested (see [5]). 
- Labour input: Similar to the use of other resources in the production process the use of labour should be reflected by the market price (net tax factor 1.17).

- Capital goods: The costs associated with the inputs of capital goods (i.e. the equipment, the machines and the buildings) normally enter a financial costbenefit analysis in the form of the assumed annual loss of value associated with the usage of the capital goods in the production process. In the welfare economic analysis the total investment amount, plus the net-tax factor, is divided equally over the assumed period of operation with a capital recovery factor. Investing in capital goods in one project gives rise to opportunity costs - foregone returns or foregone consumption. In financial calculations these foregone returns are reflected in the discount rate chosen to derive the net present value of the annual cash flows. To account for the opportunity costs of investments the annual investment amount is increased with a 'return on investment factor for capital'. The term most often used for this factor is 'shadow price on capital'.

- This return on investment factor is equal to the present value of one DKK invested in the second-best project alternative and is calculated using an (economic) investment rate and the social time preference rate for discounting. Møller [6] recommended an economic investment rate of 6\% which is in accordance with the recommendations for socioeconomic cost-benefit analysis of the Danish Ministry of Finance [7].

After calculating the annual investment amount by using a capital recovery factor and taking into consideration the opportunity costs from foregone investments by multiplying the annual amount with the return on investment factor, the resulting amount is then increased with the net-tax factor for either domestically or internationally traded goods.

Present and expected market prices are used for the measurement of the changed use of marketed goods, but the largest problem is the valuation of the non-marketed goods, i.e. the environmental effects.

\subsection{Quantification of the environmental effects}

Last but not least the environmental consequences are assessed quantitatively in physical terms as well as in monetary terms, whenever possible. The environmental consequences comprise air emissions, but also emissions to soil and water, comprising emissions of $\mathrm{SO}_{2}, \mathrm{NO}_{x}$, particles, $\mathrm{CO}_{2}$, but also heavy metals, dioxin and chemicals. The emissions to air mostly stem from the combustion process. The emissions to soil and water mainly stem from the deposit of waste and slag, which is a residual product from the combustion. Ground- and surface water can also be damaged because of emissions of percolation from the deposits. The magnitude of transport influences the air emissions.

These emissions cause damage. On the positive side, there are benefits when heat and energy are produced as residual products from the combustion process, and some of the metals can be reutilised as well. Of the greatest difference between the financial and the welfare economic assessment is that the welfare 
economic assessment comprises the environmental effects stemming from each of the processes, but as mentioned it is necessary to quantify the environmental effects as far as possible in monetary terms, to include them in the welfare economic assessment.

Because these environmental effects are not traded on a market, these goods have no price. Exceptions are heat and metals, however. Accounting prices for environmental goods can be used as prices for the non-marketed goods, but should be interpreted with caution because of the uncertainty. These accounting prices are so far as possible built on existing knowledge about the revealed or stated preferences in the population. Many methods exist to reveal the preferences through willingness to pay-assessments, and both revealed and stated methods are commonly used to elicit the social value of non-marketed public goods. These elicitations make the willingness to pay for these goods comparable to the willingness to pay for other, traded goods. Alternatively, accounting prices for the environmental goods can be elicited by estimating damage costs, or by using cost-based prices for a 'statistical life', where the probability of death and illness as a consequence of the emissions is used in connection to the price for the statistical life (cf. $[8,9]$.

Table 1: $\quad$ Accounting prices for environmental effects and emissions.

\begin{tabular}{|c|c|c|c|}
\hline & \multicolumn{2}{|c|}{ Accounting price } & Reference \\
\hline $\mathrm{CO}_{2}$ & $\mathrm{DKK} / \mathrm{kg}$ & 0.02 & Andersen and Strange 2003 \\
\hline Methane & $\mathrm{DKK} / \mathrm{kg}$ & $x$ & No account exist \\
\hline Particles $(\mathrm{PM} 2,5)^{\star *}$ & $\mathrm{DKK} / \mathrm{kg}$ & 1308 & Andersen et al. 2004/p. 8-9 \\
\hline Particles (PM10)* & $\mathrm{DKK} / \mathrm{kg}$ & 783 & Andersen et al. 2004/p. 8-10 \\
\hline VOC & $\mathrm{DKK} / \mathrm{kg}$ & & No account \\
\hline $\mathrm{NO}_{\mathrm{x}}$ & $\mathrm{DKK} / \mathrm{kg}$ & 83 & Andersen et al. 2004/p. 8-9 \\
\hline $\mathrm{SO}_{2}$ & $\mathrm{DKK} / \mathrm{kg}$ & 583 & Andersen et al. 2004/p. 8-9 \\
\hline $\mathrm{CO}$ & $\mathrm{DKK} / \mathrm{kg}$ & 0 & Andersen, pers. comm.. \\
\hline $\mathrm{HCl}$ & $\mathrm{DKK} / \mathrm{kg}$ & $x$ & No account exist \\
\hline $\mathrm{Cd}$ & $\mathrm{DKK} / \mathrm{kg}$ & $x$ & No account exist \\
\hline $\begin{array}{l}\text { Lead and other } \\
\text { heavy metals }\end{array}$ & $\mathrm{DKK} / \mathrm{kg}$ & 13142 & $\begin{array}{l}\text { Andersen, pers. comm. Spadaro } \\
\text { and Rabl, 2003** }\end{array}$ \\
\hline Arsenic & $\mathrm{DKK} / \mathrm{kg}$ & 5358 & $\begin{array}{l}\text { Andersen, pers. comm. Spadaro } \\
\text { and Rabl, 2003** }\end{array}$ \\
\hline Dioxin & $\mathrm{DKK} / \mathrm{kg}$ & $\begin{array}{r}9,000,00 \\
0\end{array}$ & Andersen et al. 2004 \\
\hline
\end{tabular}

${ }^{*}$ Calculated from PM2.5 by division by 1.67 (Andersen, pers. comm.)

** Calculated as an average for cities between 100,000 and 500,000 inhabitants.

Based on accounting prices from the EU-funded BeTa.system (benefit tables) [10] and the ExternE [11] Andersen et al. [9] have elicited accounting prices for air emissions, and the prices are used in the welfare economic assessments in the present study. The prices are apparent from table 1. In connection with waste 
disposal Andersen and Strange [8] pinpoint that the most important damage effect is that from lost amenity value. No Danish studies are performed until now to qualify if this holds under Danish conditions, and therefore the potential amenity loss is not included in the present analysis.

The accounting prices used are apparent from table 1.

The emissions of methane, $\mathrm{HCl}, \mathrm{VOC}$ and $\mathrm{Cd}$ have not been possible to estimate because of lack of data. One of the assumptions behind the estimations of the accounting prices is that the effects are accounted for citizens in 'averagesized' cities between 100,000 and 500,000 inhabitants. The accounting prices change for $\mathrm{SO}_{2}$ and particles if the basic assumptions for larger cities above 500,000 inhabitants are used, but the other prices are not changed, and therefore, the prices estimated for average cities between 100,000 and 500,000 inhabitants are used for the estimations.

In addition to these direct environmental consequences there is also production of heat and energy from the combustion process, and this is positive as conventional energy sources are substituted. Hereby the emissions and damage costs from the production and use of these energy sources are avoided. These substitution effects are included in the assessments. The processing of copper and chromium for market purposes likewise displaces the emissions and waste. Energy, heat, copper and chromium are priced in welfare economic prices, and the value of the avoided environmental consequences is included in the assessments.

Finally, only domestic consequences are considered in this analysis, in other words potential consequences outside Denmark are not considered.

Furthermore, in this welfare economic analysis we have assumed that the project implies a choice of technique, where there will be no sunk costs. This assumption is chosen to avoid that choices are dominated by investments and decisions already made, and hereby avoid decisions that will be inefficient in the long run. The time horizon for the analysis follows the lifetime of the plants and technologies; from 10 to 30 years. In this analysis the scenario covers the period from 2000 to 2030 .

\section{Results and conclusions}

The analysis indicates that the collection potential is not a limiting factor for the plants and the processing of the wood, but there is uncertainty about the quantity of the wood collected by the public schemes. Using samples of the quantity collected by these schemes suggests a minimum and maximum scenario.

In the financial economic analysis illustrated in Figure 1, the difference between methods of processing can be seen. These figures are estimated without the environmental effects. Minimum and maximum scenarios are indicated by 'min' and 'maks'.

Making a welfare economic analysis, including the environmental consequences the differences between the methods are clearer, cf. figure 2. The figure shows the welfare economic costs of the four methods, where the costs are calculated as the costs in DKK of processing one ton of impregnated waste 
wood. The figure also contains some sensitivity analyses in order to provide more robust results.

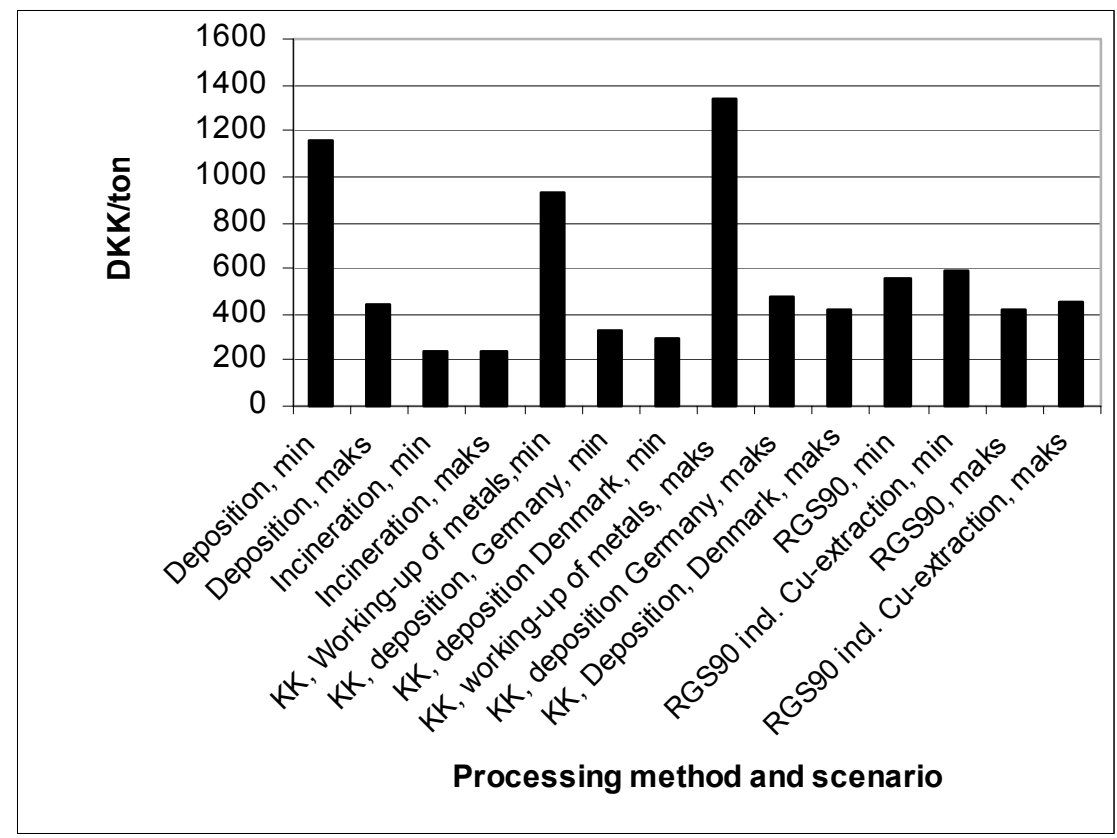

Figure 1: Economic costs (DKK/ton processed impregnated waste wood) for both min. and max. scenario (2004/2005-prices) [13].

Of the four methods it can be seen that incineration and Kommunekemi (with deposition of metals) are the cheapest. The reason is partly that the heat of the processes is used, and thereby other more polluting fuels are displaced. In the figure it is also worth noticing that deposition is quite expensive if the use of heat does not displace fuels. Ordinary deposition neither utilises the wood by recycling nor the energy in the wood. If one only looks at the direct costs of the processes, and does not try to estimate the value of the environmental consequences, the differences in methods are much smaller, as can be seen above, re figure 1 .

The environmental consequences are hard to estimate the value of. The potential long-term effects of leaching from deposition and the effects of heavy metals in slag and discharge water are not included in the report, but $\mathrm{CO}_{2}, \mathrm{NO}_{\mathrm{x}}$, $\mathrm{SO}_{2}$, arsenic, dioxins, lead and other heavy metals are. To make the results as robust as possible several sensitivity analyses have been made, e.g. by changing the prices on the environmental effects, changing the rate of interest and assuming different transport costs. The results of these analyses are unambiguous in their ranking of the methods, but they obviously change to which degree the methods differ. 


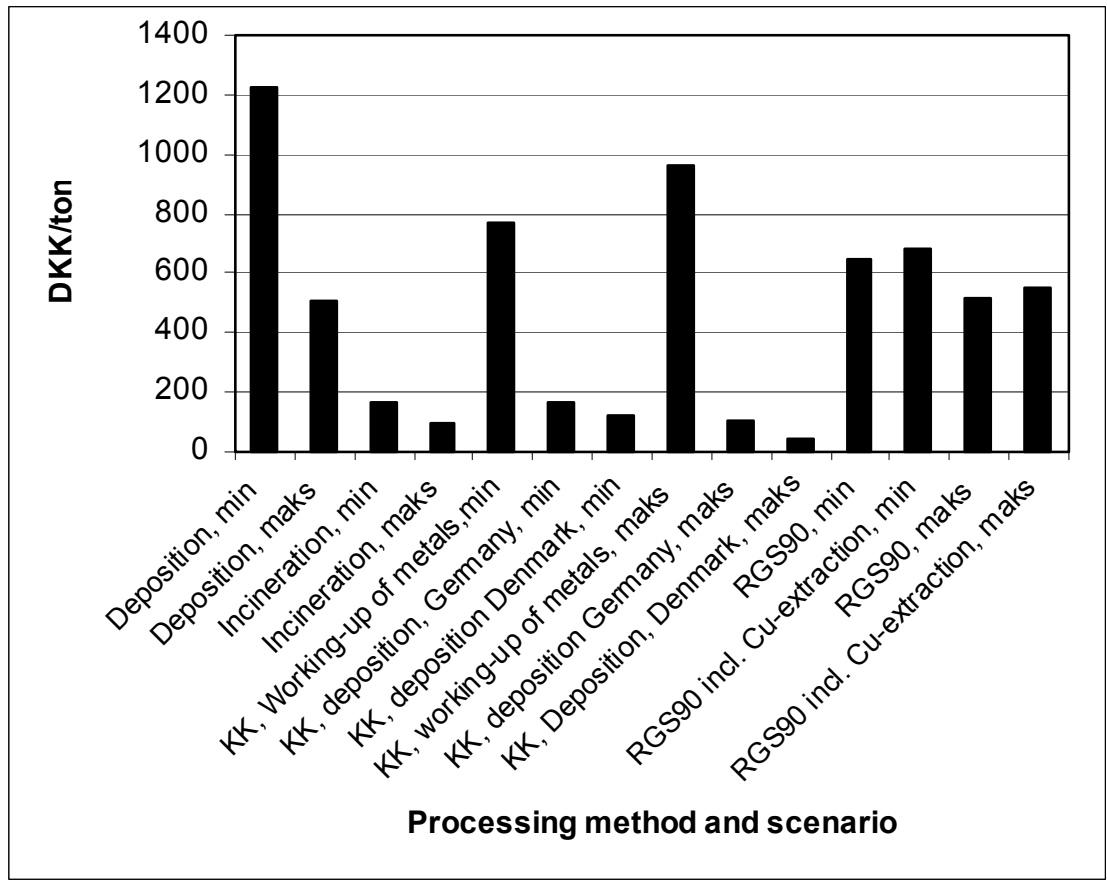

Figure 2: Welfare economic costs (DKK/ton processed impregnated waste wood) for both min. and max. scenario (2004/2005-prices) [13].

The difference between the results in figure 1 and 2 mainly comes from the fact that the environmental consequences are only taken into account in the welfare analysis in figure 2. The gasification and the incineration processes improve their position by displacing other more polluting fuels. If it is assumed that the wood stemming from RGS90 Watech's process is used to produce electricity or heat it is not unrealistic that RGS90 Watech's method would be competitive to incineration and gasification.

Concluding on the results does not give occasion for believing that the hierarchy of waste should be ignored when choosing the optimal processing of impregnated waste wood. Deposition, however, seams to be expensive given the method neither recycles nor utilises the energy.

\section{References}

[1] The Danish EPA, Waste 21, Ministry of the Environment, 1999.

[2] The Danish Government, Waste Strategy 2005-08 (Affaldsstrategi 200508), Copenhagen, (2003).

[3] Centre for knowledge about waste (in Danish), Imprægneret træ. Deponi. Forbrænding. http://www.affaldsinfo.dk/ 2004. 
[4] Møller, F., Andersen, S.P., Grau, P., Hussom, H., Madsen, T., Nielsen, J. \& Strandmark, L., (in Danish), Samfundsøkonomisk vurdering af miljøprojekter, Danmarks Miljøundersøgelser, Miljøstyrelsen og Skov- og Naturstyrelsen, 2000.

[5] Birr-Pedersen, K., Welfare Economic Cost-Benefit Analysis, Working Paper from the project "ARLAS", National Environmental Research Institute, 2001.

[6] Møller, F. (in Danish), Forrentningsfaktoren og diskontering (supplement to) Samfundsøkonomisk vurdering af projekter, Danmarks Miljøundersøgelser, 2001.

[7] Ministry of Finance (in Danish), Vejledning $i$ udarbejdelse af samfundsøkonomiske konsekvensvurderinger, Copenhagen, 1999.

[8] Andersen, M.S. \& Strange, N. (in Danish with an English summary), Miljøøkonomiske beregningspriser. Forprojekt. Danmarks Miljøundersøgelser. Technical report, National Environmental Research Institute, no. 459, 2003.

[9] Andersen, M.S., Frohn, L.M., Jensen, S.S., Nielsen, J.S., Sørensen, P.B., Hertel, O., Brandt, J. \& Christensen, J. (in Danish with an English summary), Sundhedseffekter af luftforurening - beregningspriser, Technical report from NERI, no. 507 2004. www.dmu.dk

[10] Spadaro J.V. \& Rabl, A., Pathway Analysis for Population - Total Health Impacts of Toxic Metal Emissions, 2003.

[11] European Commission (EC), ExternE, Externalities of Energy (Vol. 1), Summary, 1995.

[12] Kristensen, O., Note on the composition of impregnated waste wood (in Danish), 2003.

[13] Hansen, V., Cramer, J., Hasler, B., Larsen, A. \& Bruun Poulsen, P. (in Danish with an English summary) Miljø- og samfundsøkonomisk analyse af indsamling og behandling af imprcegneret affaldstrce, Miljøstyrelsen, (forthcoming). 